\title{
Chapter 19 The Impacts of the Sustainable Development Goals on Forests and People - Conclusions and the Way Forward
}

Georg Winkel, Glenn Galloway, Carol J. Pierce Colfer, Wil de Jong, Pia Katila and Pablo Pacheco

\subsection{Introduction}

Since time immemorial, forests have served as a foundation for human development. Across the globe, the evolution of societies, and their welfare, has been closely connected to various uses of forests. Through this close association, humans have shaped and transformed forest landscapes in many parts of the world. The forest transition literature is illustrative of this connection, focusing on the interrelation of humans and forests along a development trajectory, and seeking to explain the regularity of a particular pattern across societies: that forest cover declines until a turning point - transition - after which gains in forest cover due to natural regeneration and plantations overtake deforestation losses (Angelsen and Rudel 2013, Mather 1992; see also Chapter 1).

Drawing on an analogy to ecosystem research, the forest-people interface can be perceived as an ongoing (socio-ecological) co-evolution process. This co-evolution of people and forests is characterised by constant change. Relationships range from symbiosis, to co-existence, to sometimes predatory exploitation that can even lead to extinction (i.e. permanent forest destruction). As with co-evolution in ecosystems, abundance and mutation are important driving factors of the process. For the forest-people interface, abundance relates to how many people are present in relation to a forest area, possibly transforming the demand for ecosystem services from a sustainable pattern into an unsustainable one. Mutation acts as an analogy for both the evolving human needs and desires towards forests (e.g. related to economic growth and accumulation) and the new technical capacities people develop to more efficiently manage, but also exploit or destroy, forests. Both factors determine the human side of this socio-ecological system.

On the side of forest ecosystems, such human interventions have led to adaptations, major changes of the forest landscape with shifting species compositions, altered biological dynamics and processes, and, taken to the extreme, have led to their transformation into agricultural or urban ecosystems. 
The SDGs may impact this co-evolution process from multiple perspectives. They merge several previously separated policy concepts into a comprehensive - though not necessarily coherent - development agenda, a 'snapshot' of different elements of development thinking at a certain time. This agenda is so broad that it allows many societal groups with partially contradicting demands and interests to identify with it. At the same time, it provides space for interpretation and adaptation at those levels where trade-offs need to be resolved and priorities need to be agreed upon.

In this chapter, recalling the main purpose of this book - to explore the impacts of the SDGs on forests and people - the attempt is made to offer broad conclusions on key lessons learnt from the comprehensive assessment carried out in this book. This is done with a view to providing guidance for the future co-evolution of people and forests in a changing world, in a way that acknowledges dependency and stewardship and works towards symbiosis over parasitism.

\subsection{Lessons Learnt}

\section{1) While forests play a critical role in sustainable development, the SDGs will impact forests and the people dependent on them in a multitude of ways}

This first conclusion is at the heart of this book and is supported by the comprehensive evidence presented throughout. Forests are critically important for human development, not only from a historical perspective but in today's world as well. They are one of the three major human life-supporting ecosystems of the planet, along with agricultural lands and oceans. They currently cover one-third of the global land area, contain 80 per cent of terrestrial biomass and provide habitat for more than half of the world's known terrestrial plant and animal species (Aerts and Honnay 2011; see also Chapter 15). Approximately 1.6 billion people directly depend on forests and the ecosystem services they provide for their livelihoods, and a staggering 2.8 billion people, mostly in the developing world, burn woodfuel for their basic energy supply (see Chapter 7). Furthermore, everyone on this planet depends on the world's forests for their essential role in global carbon, water and nutrient cycles, which impact climate, food and urban systems (see Chapters 13, 6, 2 and 11, respectively). Clearly, human well-being and development hinges on the existence of forests and their ecosystem services. This needs to be acknowledged and considered by policymakers who pursue progress towards sustainable development around the world.

While research has shown the universal scale of dependency of humanity on forests, this book has shed light on the huge variety of contextual 
settings of how the connections between forests and people play out on the ground. Relations range from emotional and spiritual connectedness, e.g. in relation to recreation that is perceived being a priority in several urbanised agglomerations (Chapter 11), up to total dependence for livelihoods in remote rural areas. Significantly, the comprehensive assessment carried out in this book shows that the needs and interests of people do not always align with the vision to maintain permanent forests. While forests provide critical ecosystem services for societies, there are also cases where potential 'disservices' exist, e.g. relating to specific forest-borne human diseases (Chapter 3). Furthermore, increasing populations as well as economic and social development have been and often continue to be accompanied by the exploitation, degradation and loss of forests, particularly in the early stages of the forest transition process. Historic and ongoing global deforestation processes may serve as an indication for a higher economic and sometimes also sociocultural appreciation of other land use systems in the context of growing populations and economies. In turn, the resurgence of forest (area) in North America, Europa and East Asia indicates a new appreciation of forests after 'development' has advanced, albeit that various reasons drive this observable reforestation process (Forest Europe 2015).

Hence, societal attitudes and needs regarding forests and decisions impacting them are highly context dependent and continually evolving. Overarching trends with respect to forests in specific contexts will often reflect predominant societal (and political) conceptualisations of forests in these contexts, through the lens of socio-economic needs and demands, including the degree to which ecosystem services are recognised and valued. An important caveat relates to the fact that different people in the same country or even region possess quite distinct perceptions regarding forests, their value and people's needs with regard to their ecosystem services (Racevskis and Lupi 2006, Tyrväinen et al. 2003). When forest exploitation and loss intensify, for example, traditional forest-dependent groups will be under pressure to adapt, i.e. might be forced to change their way of life (Hobley 2005, Meyfroidt et al. 2013). Moreover, they often lack the power and political clout to influence decisions impacting their livelihoods. Meanwhile, other sectors of society for example farmers, or those in urban centres or consumers in countries located far away - through global trade and markets, might at least temporarily benefit from the additional resources mobilised and profits generated (Angelsen and Kaimowitz 1998, Angelsen and Wunder 2003). The frequent reality of 'winners' and 'losers' creates challenging questions relating to who has the right to determine the contribution of forests to human development, particularly in cases of conflicting forest management and land use options. It also calls for the necessity to agree or compromise across scales, if winners 
and losers are to be found in different spaces. The complexity and contested nature of decisions regarding forest management and land-use change will be further increased when a biocentric perspective is considered, emphasising the necessity to preserve forests for their natural beauty and ecosystem value per se. The same holds true for considering aspects of intergenerational justice that lies at the heart of the sustainability concept (UN 1987).

From the perspective of the SDGs, it can first be concluded that human needs shape the value people place on forests; these needs are again affected by different contextual factors and are interrelated to societal and political settings. This might influence the implementation of the SDGs, and with that the impact of the SDGs on forests and people in a specific context. There is no perfect forest for all, and there is no perfect forest-people interface. While humans are dependent on forests, the relationship between humans and forests is characterised by an ongoing co-evolution process that can also be dominated by antagonism. Second, people and their interests are very diverse. The implementation of one or more SDGs will, in many cases, result in winners and losers, depending on the impacts on forests. In these situations, societal groups with more resources and power to influence investments, markets and policy decisions may prevail over other groups, including possibly those whose livelihoods are most dependent on forests. Since the benefits of the SDGs are meant to be inclusive and equitable, efforts must be made to create awareness of potential trade-offs and transparent mechanisms to address them. Third, the assumption of an a priori positive correlation between forest conservation and societal development is misleading. While one critique this book offers is that the SDGs rarely mention forests explicitly and seem to underestimate the importance of forests for human sustainable development or take it for granted - this criticism should not be taken to imply that forests should be prioritised in every case. Expanding forest area is not always the best answer to complex development needs. Some of the SDGs might result in forest loss but drive social and economic development, e.g. through agricultural expansion or more space for housing and infrastructure. What is crucially important is that potential trade-offs implicit in the SDGs with respect to forests and other land uses are understood and are made transparent to societies, and that the forest-people interconnectedness is fully accounted for in societal and policy decisions. This must include thinking across different scales and generations. It must also include giving voice to forest-dependent people, who are at risk of being disregarded by efforts meant to advance the SDG agenda. Focusing attention on the potential trade-offs associated with the implementation of the SDGs and how they will impact the forest-people interface is a primary contribution this book makes to the global sustainable development debate. 


\section{2) The SDGs include distinct and partially conflicting visions for forests and people, involving the necessity to consider trade-offs and set priorities}

The main chapters of this book analyse the complex interrelations among the SDGs and their potential impacts on forest and people. These interrelations are sometimes synergistic, and other times conflictive in nature, reflecting the breadth and complexity of the Agenda for Sustainable Development. In fact, the SDGs integrate various and partly competing policy discourses, paradigms or worldviews within one framework as an outcome of a participatory negotiation process and political lobbying. These include, for instance, convictions regarding: (a) the importance of equity versus freedom/competition; (b) the importance of domestic versus global consumers; (c) the necessity to have economic growth; (d) the diverse and sometimes contradicting consumer and producer motivations and behaviour; (e) the importance of markets and rules (e.g. relating to free trade versus regulations/protectionism), and (f) the emphasis on individual versus common welfare. The SDGs and their targets can be clustered around the classical three dimensions of sustainable development and related worldviews emphasising them, distinguishing social (e.g. SGD 1: No Poverty, SDG 3: Good Health and WellBeing, SDG 4: Quality Education, SDG 5: Gender Equality, SDG 10: Reduced Inequalities, SDG 16: Peace, Justice and Strong Institutions), economic (e.g. SDG 7: Affordable and Clean Energy, SDG 8: Decent Work and Economic Growth, SDG 9: Industry, Innovation and Infrastructure, SDG 12: Responsible Consumption and Production) and environmentally focused SDGs (e.g. SDG 13: Climate Action, SDG 14 Life below Water: SDG 15 Life on Land). Major lines of potential trade-offs develop between these SDG clusters. It could be argued that the most critical underlying fault line in the SDGs, when it comes to forests and people, concerns the unresolved question of the degree to which economic growth is the solution to achieve sustainable development, or, rather, the problem that will prevent it. The following statistics are emblematic of this paradigmatic dilemma: between 1970 and 2010, the global economy tripled in size (UNEP 2016, see Chapter 9); hundreds of millions of people have escaped poverty, and economic power is distributed in a more multipolar manner across the planet than in the past. At the same time, 1 per cent of the world population is estimated to own more than half of the planet's wealth (see Chapter 9 referencing Oxfam 2016). Between 1990 and 2015, global forest cover decreased by 3.1 per cent, to 30.6 per cent of the global land area, with most forest loss occurring in the tropics (FAO 2015, see Chapter 15); 4 of 10 planetary boundaries have been crossed and others are seriously at risk (Steffen et al. 2015). The quandary is the increasing tension 
between economic development (growth) and an ambivalent and inequitable social development, as well as largely negative environmental impacts: how can all this be addressed under the umbrella of a holistic, sustainable development paradigm? While this question extends well beyond concerns relating to forests and people, processes that play out in the forest-people interface exemplify the challenge.

The SDGs remain ambiguous on how to proceed here. Some SDG goals are more in line with a general economic growth paradigm (e.g. SDGs 8: Decent Work and Economic Growth, and 9: Industry, Innovation and Infrastructure). They promote an ecological modernisation approach in line with assumptions that economic growth, trade and technological progress will eventually resolve the trade-offs between increasing wealth and environmental exploitation through greater efficiency, accompanying better regulation and increasing shares of renewable energy and materials (see Chapter 9). Other SDG goals and their targets can be read as more 'transformational'. They address shortcomings of the current economic system and world trade, emphasising unjust distribution and environmental degradation (e.g. SDGs 1: No Poverty, 10: Reduced Inequalities, and 16: Peace, Justice and Strong Institutions). The potentially tremendous friction and contradictions between both worldviews remain unresolved.

These worldviews correspond with global forest-related discourses, which again relate to broader environmental and development discourses (Arts et al. 2010). These forest-related discourses set different priorities regarding the preservation or sustainable use of forests: finding the most feasible approach to conserve them by integrating them into (increasingly responsible) markets or shielding them from markets (assumed to remain irresponsible). Worldviews inherent to the SDGs also resonate with the 'cultural biases' in forest policy suggested by Sotirov and Winkel (2016) in reference to the Cultural Theory's global typology of society-nature interrelations, ranging from laissez faire/ free-market individualism to rule-based sustainable forest management or participatory environmental protection (Thompson et al. 1990).

It is certainly beyond the scope of this book to resolve such basic ideological controversies. Yet there is a need to acknowledge their importance, to investigate related trade-offs and conflicts implicit in the SDGs and envision measures to deal with these. Different worldviews foresee different pathways towards the sustainability of the forest-people interface. This book often conveys a rather sceptical assessment of the potential effectiveness of ecological modernisation thinking, which would assume in a simplified manner the possibility of green (economic) growth, to achieve the goals of the 2030 Agenda. Calls for a more transformative approach, possibly moving away from 
economic growth thinking to implement the SDGs, or even redesigning the SDGs themselves, figure prominently in some chapters. This criticism may, at least, be seen as an evidence-based statement that a business-as-usual development pathway will not suffice to achieve sustainable development, particularly when considering the environmental dimension and the evidence of growing inequality. It may also show a certain scepticism about whether the SDGs (and ecological modernisation thinking) have enough transformational power and ambition to overcome the inertia of the current pathway. Yet, how far ecological modernisation can bring the co-evolution of forests and people onto a more sustainable track in different settings remains to be seen. An alternative mix of fewer social and environmental science authors and more engineers and neoclassical economists might have assessed the status quo and prospects for forests and people in a more positive or optimistic fashion, e.g. regarding the potential for forests to contribute to a low-carbon economy and society of the future through efficient use (e.g. Hetemäki et al. 2017).

Ultimately, it will be at least partially a matter of opinion how far ecological modernisation thinking can go and whether (more) transformational approaches are needed to balance the sustainable development of forests and people. Combining this with the initial finding herein - that there is no perfect forest for all demands, and that trade-offs are frequent among different forest ecosystem services, and more so, among different land use types - calls for the need to engage in the SDG implementation across ideological boundaries. This will include making the inherent frictions between major governance, related land use and forest management paradigms visible, but also investigating how different paradigms play out in a specific implementation context. Yet, this also needs a better understanding of what implementing the SDGs might actually mean - a point for reflection under the next lessons learnt point.

\section{3) The SDGs impacts on forests and people are context dependent and may be locked into path-dependent socio-economic development trajectories, but global interdependencies remain}

In an ideal world, wise men and women in government would sit together and develop a coherent implementation plan for the SDGs that engages all sectors of society in order to achieve the SDG targets in a well-coordinated implementation process. However, taking into consideration early, oftencited lessons learnt from policy implementation research (Pressman and Wildavsky 1984), a more realistic view recognises that SDG policy on paper 
will not necessarily translate into corresponding implementation practices on the ground.

While theoretical assumptions about pathways of implementation/influence can be made (see the model in Chapter 18), and national reports indicate that several activities are taken up at different levels to implement the SDGs, a key finding of this book is that the real effects of SDG implementation - and the interplay among them - are often not (yet) known. The assessment of each SDG for potential impacts on forests and people had to assume it would be implemented, and/or to estimate how implementation could play out, and then anticipate impacts of such assumed implementation in different contexts. In addition, authors assessed evidence on trends that are currently occurring, but without being able to connect them (at this point in time) causally to the SDGs.

This limitation of the book is unavoidable, as there is no better evidence yet available. Clearly, there is a need for research to better understand alternative impact pathways of how the SDGs unfold in different contexts. This could, for instance, take the format of a comparative SDG study across several countries. Nevertheless, this book has provided a substantive basis for estimating real-world impacts of the SDGs. In this regard, one key finding from this book is that the same SDGs and the same targets will often lead to different effects in different contexts. Countries will set their own priorities, and people at the forest-people interface will harbour different attitudes regarding these priorities. Furthermore, the prioritisation will probably merge with past socio-economic and political development trajectories that determine forest governance and management. Frankly, it would be naive to assume that the SDGs could be implemented without fitting them into pre-existing sectoral development pathways. This integration into the existing policy and socio-economic context will largely determine their potential impacts. It will also result in different spatial-temporal responses, and related impact patterns, in relation to the SDGs.

A highly interesting question, then, is if it is possible to detect similar context patterns resulting in comparable SDG implementation routes and impact pathways. In other words, will countries with similar socio-economic and ecological situations set the same priorities regarding the SDGs, resulting in similar outcomes? Moreover, can we then assume a certain temporal succession in the SDGs' impact over time, e.g. along the forest transition curve? This could, for instance, play out through a shifting focus from social SDGs towards environmental ones regarding forests - from food or fighting poverty to biodiversity - with economic ones likely remaining important throughout the transition process. If such a sequential order exists, it poses 
the uncomfortable question of whether (some) forest destruction needs to be accepted when it enables development and decreases poverty, and this way again later might enable a less exploitative forest-people interface, following the forest transition thinking.

Yet, development pathways and directions and the impact of contextual factors do not seem to follow one consistent pattern. Taking a closer look at the forest-people interface in several countries reveals that many different development states relate to different forest-management and land-use situations. Context dependency results in distinct forest-people interface coevolution pathways that can be identified across countries: e.g. a 'boreal timber economy trajectory', an Anglo-Saxon 'splitting the land in conserved and heavily used forests trajectory', a Central European 'integrated forest management trajectory', or a 'tropical deforestation and then forest restoration through plantations and natural regeneration trajectory'. These trajectories relate specific ecological forest settings to specific socio-economic situations and cultural paradigms and convictions about the forest-people interface. Depending on a country's trajectory, the SDGs may not only be interpreted and implemented differently, but may also result in quite distinct impacts on both forests and people. Major processes along the forest transition timeline may then add to these spatially and contextually distinct development pathways.

Context can play out even more dramatically. In several forest-rich world regions, poverty, rapid population growth or even violent conflicts are prevalent. In such contexts, the SDGs - if recognised at all - will be interpreted differently, with emphasis on those basic values that ensure survival and livelihoods. Forest (over-)exploitation may seem more justified in these contexts if it is meant to address local basic needs, yet this does not lessen the environmental footprint. With that comes an important message: while context will be key to the SDGs impacts on forests and people, the spillovers and interconnections across scales by means of ecological process and footprints, trade, political collaboration and partnership call for continued, if not intensified, engagement across contexts and scales. Specifically, it calls for international exchange, collaboration and cooperation. Moreover, recalling the picture of the forest transition process, the crucial question remains how far the environmentally destructive patterns of the process can be mitigated, or even reversed, without curbing development. This may, however, also include the necessity to reflect on what socio-economic development means in relation to its environmental impact. The SDGs do not provide a consistent response to this major strategic question. Responses will likely differ depending on the specific forest-people interface co-evolution pathway at hand. 


\section{4) There are fundamental values and principles that may guide sustainable development related to forests and people}

In the first three lessons learnt, we have focused on the multifaceted nature of the SDGs and their relation to forests and people. We have shown that the SDGs set a normative framework, but one full of potential contradictions. We have emphasised that there is no perfect forest for all people and demands. We have hence indicated the necessity to regulate trade-offs relating to values, interests and convictions about how to best govern sustainable development at the forest-people interface.

In this section, we partially reverse this relativism and seek to (1) elicit some fundamental consensual values of the SDGs that might guide their implementation in relation to forests and people globally, and (2) consider if there are related fundamental procedural principles that can guide decisionmaking in more detail during the implementation.

First, it is critical to recall fundamental principles of global importance such as human survival, human rights, peace, justice, welfare and democracy, or referring to the Agenda 2030: peace, planet, prosperity, people and partnership. Most on this planet will agree that these principles need to be respected (which does not mean that they always are). Implementing them in the context of the forest-people interface should be beyond dispute.

Second, forest-specific considerations may be added to the list. These may refer to the necessity to consider the long-term cycles of forest ecosystems, connected to the challenge of irreplaceability. This means, for instance, that it can be nearly impossible to restore a primary forest once it has been destroyed, and it is impossible to regain a species that has been lost. This also relates to aspects of intergenerational justice and equity. In a more classical forester's understanding, this includes the basic axiom that a massive overuse of forest biomass will lead to an undersupply in the future. To this list, aspects of space and related justice need to be added - e.g. the regional benefit of cutting down a forest may jeopardise climate change mitigation, a globally important ecosystem service. Moreover, the multiple values of forests for society need to be considered. These considerations may lead to a fundamental forest-related SDG implementation principle: to maintain resilient forest landscapes that, now and in the future, provide ecosystem services that respond to various societal demands originating from people across multiple locations, and with evolving demands over time.

Third, connecting this forest-specific principle to the fundamental humanrelated ones leads to acknowledging the special rights of those half-a-billion people that directly depend on forest ecosystem services, including the right to maintain forest-based livelihoods. 
Fourth, recalling the contradicting targets and worldviews that are conceptually embedded in the SDGs, another fundamental principle could address the process of implementing the SDGs. Here, postulating a basic principle of good governance in resolving the trade-offs inherent to the SDGs is recommendable. This includes the necessity to accept that a diversity of viewpoints, societal needs, cultural values and interests exists, and that these should be considered in forest policy and management decision-making. Different groups should have access to the policymaking and implementation process at all levels; transparent decision-making processes perceived by everyone as fair and effective could be the procedural key recommendation facing nonresolved value and interest conflicts.

\section{5) Sustainable development at the forest-people interface will not happen without recognising and tackling major driving forces of (un)sustainable development in general, and integrating forest governance and management into a broader landscape perspective}

One important conclusion from this book is that the fate of the world's forests, and of forest-dependent people, will mostly be decided outside the forests, and mostly not by forest-dependent people. The continuing expansion of agriculture, for food and feed production, is by far the largest direct driver of deforestation, causing approximately 80 per cent of forest loss (see Chapter 2). This means, first, that the agricultural sector and the larger context of factors driving that sector are crucial for the sustainable co-evolution of forests and people. Secondly, recalling Figure 18.1 in Chapter 18, the entire socio-ecological system determining the planet's land use needs to be assessed to understand the impacts of the SDGs on the forest-people interface. Essentially, this means looking into major driving forces such as population and economic growth, consumption and its environmental footprint, climate change, corruption and failing governance, technology (access and funding), the fundamental role of culture and religion in driving behavioural patterns, and the prevalence of wars and violent conflicts in many world regions. The assessments done in this book raise questions regarding the degree to which the SDGs are suited to address these overarching driving forces of (un-)sustainable development. For instance, Chapter 3 emphasises the critical importance of global population growth on the depletion of the planet's natural resources while pointing out that this issue is not really addressed in the SDGs for being politically inappropriate. Regarding economic growth, the ambivalent positioning of the SDGs on this driver was discussed earlier. At the same time, the planetary boundaries theory (Steffen 
et al. 2015) stresses that the impact of increasing demands for resources by a growing population is already exceeding the ecological capacities of the planet, with forests playing a prominent role in providing these (diminishing) capacities. It may be the 'big three' driving forces - (1) ongoing (albeit flattening) population growth, (2) economic growth together with a fixation on short-term profit, and (3) the steadily increasing global environmental footprint and environmental pressures resulting from it, all three interwoven with a complex array of socio-economic path dependencies, cultural and religious barriers to change and learning - that will determine the ultimate outcomes of (un-)sustainable development on this planet. These elephants in the room are also at the core when it comes to the forest-people interface: as long as forests are largely considered (and needed?) as a resource to be converted into often intense food and commodity production systems, and as long as global pressure drives this land-use change, deforestation and loss of forest ecosystem services will continue.

One more elephant in the room may also be of critical importance here: sustainable investment and financing. As long as vastly more money is invested in activities driving large-scale forest conversion, mostly with the aim of expanding industrial agriculture, than is invested in forest conservation, including management and/or small-scale agroforestry (Chapter 17), it is obvious that attempts to achieve sustainable management of forest landscapes will be difficult to accomplish. Ultimately, it is also the lack of recognition of the full economic potential of forests, including their wide spectrum of often non-valorised ecosystem services, that leads to the disregard and elimination of forests for the purpose of economic development and profits.

The challenges are thus (a) how to manage and possibly curb the major growth driving forces (greater numbers of people with a desire to live well and prosper), and (b) how to decouple demographic and economic growth from environmental impacts, including carbon emissions. Forests may play an important role in such a decoupling, e.g. through innovation and valuation of the ecosystem services they provide as pillars for a green and sustainable economy (Winkel 2017). At an operational scale, innovative, cross-sectoral governance arrangements and management will be needed to develop and promote forest landscapes that sustainably integrate a mosaic of different uses. This calls for an integrated landscape approach that goes beyond narrow sectoral perspectives and reaches out to include the various value chains associated with the use of forest ecosystem services. With their many links to different sectors and people, forests play a critical role in facilitating such an approach, if their multifaceted importance is correctly accounted for. Research that investigates the full societal and economic importance of forests through 
accounting for their full ecosystem services spectrum can support this transformation. It will be important to involve adjacent powerful societal sectors into this approach, increasing the possibility to diversify forest-related development, and increasing the likelihood for forests to remain a permanent part of the landscape in the future.

The implementation of such an integrated landscape approach will also mean taming one last elephant that inhabits the forest habitat and is difficult to approach: the multifaceted informal/illegal activities taking place in the world's forest. Estimates indicate that the greatest proportion of the forest-related economy operates in the informal sphere (World Bank 2016). The spectrum ranges from informal local economies and livelihoods based on customary rights connected to traditional knowledge and forest uses to corruption and criminal forest exploitation through large-scale illegal logging. This reality characterising many forested regions in the world diverges from the idea of a systematic implementation of the SDGs and associated targets through government in line with the ideal of Plato's just state. Yet, research has repeatedly shown that attempts to formalise the informal sector have often had ambivalent outcomes. In some cases, enforcement not only targets criminal behaviour, but also traditional use forms and customary community rights harmfully impacting the very people the SDGs are supposed to benefit (McDermott et al. 2019). Addressing the informal dimensions of the forestpeople interface in any approach aiming to advance sustainable development is essential. It must be done, however, with caution, recognising the importance of this sector for local livelihoods, traditional forest uses and related forest knowledge.

\section{6) The planet is changing rapidly - key elements of the success of the SDGs will require learning that results in adaptation of targets and their implementation}

While the SDGs are a comprehensive development agenda, they are unavoidably bound to the specific perspective resulting from their negotiation. Moreover, their potential impacts during implementation will evolve in relation to changing socio-economic and ecological conditions. In the case of forests, for instance, climate change is resulting in changing disturbance patterns and changing species distributions. Those will alter the capacity of forests to provide ecosystem services for society, and of people to manage these forests. Also, societal needs and demands towards forests will change, inter alia, through processes of urbanisation and globalisation. These developments cannot be projected with precision for periods of a decade or more. 
Together with the frequently stressed context-dependence of the SDGs, they can be read as a call for an adaptive implementation process of the SDGs. Such a process is characterised by monitoring and evaluation to leverage progress through continual learning, and to put into place feedback loops to adjust political targets and measures to attain them. A focus on meaningful, partially qualitative indicators will be needed, complementing quantitative ones. Moreover, much emphasis should be given to the processes of how indicators are developed, how monitoring is conducted and how feedback is processed. Participatory bottom-up approaches that are mindful of specific forest contexts and that empower local people to assume a key role in monitoring could favour the advancement of locally suitable sustainable development trajectories. Recalling the challenging question of the importance of economic growth as a driver of or challenge for sustainable development, measurements of economic growth and well-being could be broadened to take into account environmental and social impacts. This may include going beyond GDP growth by accounting for natural capital stock in combination with broadened socio-economic metrics (see Chapter 9). Knowledge and education, specifically the willingness to share knowledge and learn, will be critical to enhance informed decision-making in the SDG implementation process. New means in information technology could hold substantial promise for increasing transparency regarding the co-evolution process of the forest-people interface locally, but also at the global level. They can, inter alia, bring consumers and producers closer to each other, and thus be fundamental for fostering greater awareness and shared responsibility for achieving shared goals. In such a setting, the SDG implementation ideally becomes a continuous learning process of how to adapt and improve sustainable development at the forest-people interface based on traceable outcomes on the ground. This book seeks to encourage such a learning process by providing empirical evidence on past efforts, and evoking interest to explore unknown territories that will inevitably await practitioners that seek to further the attainment of the SDGs, while advancing sustainable development at the forest-people interface.

\subsection{Outlook: The Way Forward}

What can a reader who wants to help advance sustainable development at the forest-people interface take away from this book? In short, this chapter concludes that:

- Forests are a key base for sustainable development.

- The SDGs will impact forests and the people dependent on them in many ways. 
- The SDGs include partially conflicting visions for forests and people, making it necessary to consider trade-offs and to set priorities.

- The SDGs' impacts on forests and people are highly context dependent.

- There are fundamental values and principles that may guide sustainable development related to forests and people.

- There are major driving forces of (un)sustainable development that need to be tackled to advance forest governance and management.

- There is a necessity to continuously learn, and adapt, in the process of working towards sustainable forest management at the forest-people interface.

These lessons learnt are critically important for advancing sustainable development at the forest-people interface. They are, however, in no way meant to constrain creativity, inspiration and action at this interface. The issues at stake are often terribly complex, and ambiguity is at every corner. However, though the magnitude of some of the challenges is new, several patterns of the challenges ahead are not new to humanity. It is not the first time that societies have faced limits of growth; that deforestation, overexploitation of forest resources and dwindling forest ecosystem services are raising concerns; or that there is striking inequality. All of these patterns have existed repeatedly - at the regional scale - in the history of humanity. Scarcities and paucities have frequently been the source of what is perhaps the best humanity has to offer: creativity, the ability to innovate and to develop further. Importantly, never before have the technological, scientific and informationrelated capacities been more advanced to support such innovation. This is not meant to naively promote green growth and ecological modernisation. The point we make here is that it is critical to trust in the ability of mankind to overcome a development challenge, one with a magnitude and impact never before experienced, but with often familiar basic patterns. Human creativity, confidence and readiness to innovate is needed for policymakers to work across sectoral silos (e.g. connecting agriculture and forestry), for scientists to critically ask the right questions (e.g. thoroughly monitoring the interdependencies of people and forests) and to communicate evidence frankly, and for forest practitioners and local people to innovate on the ground and try new approaches for integrating manifold societal demands. Obviously, there are frequently policy silos, power games, economic interests and reform-resistant or sometimes even corrupt structures dominating the land use sectors. This requires visionary policymakers to overcome these hurdles, and path-breaking business entrepreneurs to think beyond conventional economic pathways. Policy, business, civil society, science and forest-practice innovators are 
needed to advance the co-evolution of forests and people on a sustainable track, and their thinking needs to go beyond well-established channels to tackle the major issues at hand.

Hence, it is at the human part of the co-evolution process at the forestpeople interface where changes need to happen and innovation needs to advance. Rich forests have existed on this planet since long before humans arrived; it seems unlikely that humans would survive a future without these rich forests given their tremendous importance for the planet's ecological and socio-economic systems. For a reader pessimistic about the human capacity to overcome the danger of our own impact, this book perhaps offers little more than a detailed exploration of where those impacts lie regarding forests. For the confident reader, however, this book can hopefully be a huge source of inspiration and guidance for possible changes towards sustainable development for both forests and people. In this sense, such readers may feel very much encouraged to engage in a holistically understood, but locally shaped, sustainable development of societies and their natural resource base. Such sustainable development, as this book has shown, will be impossible to envision without one of the most astonishing and admirable part of nature on our planet - the world's unique and beautiful forests.

\section{References}

Aerts, R. and Honnay, O. 2011. Forest restoration, biodiversity and ecosystem functioning. BMC Ecology 11(1):29.

Angelsen, A. and Kaimowitz, D. 1998. Economic models of tropical deforestation. A review. Bogor: Center for International Forestry Research.

Angelsen, A. and Rudel, T. K. 2013. Designing and implementing effective REDD+ policies: A forest transition approach. Review of Environmental Economics and Policy 7(1):91-113.

Angelsen, A. and Wunder, S. 2003. Exploring the forest-poverty link: key concepts, issues and research implications. CIFOR Occasional Paper 40. Bogor: Center for International Forestry Research.

Arts, B. J. M., Appelstrand, M., Kleinschmit, D. et al. 2010. Discourses, actors and instruments in international forest governance. In Rayner, J., Buck, A., and Katila, P. (eds.) Embracing complexity: Meeting the challenges of international forest governance. A global assessment report. IUFRO World Series no. 28. Vienna: International Union of Forest Research Organizations (IUFRO), pp. 57-74.

FAO 2015. Global Forest Resources Assessment 2015. How are the world's forest changing? Rome:

FAO. Available at: www.fao.org/3/a-i4793e.pdf (Accessed 28 March 2019).

Forest Europe 2015. State of Europe's Forests 2015. Madrid: Ministerial Conference on the Protection of Forests in Europe, Forest Europe Liaison Unit. 
Hetemäki, L., Hanewinkel, M., Muys, B. et al. 2017. Leading the way to a European circular bioeconomy strategy. From Science to Policy 5. Joensuu: European Forest Institute.

Hobley, M. 2005. The impacts of degradation and forest loss on human well-being and its social and political relevance for restoration. In Vallauri, D., Dudley, N., and Mansourian, S. (eds.) Forest restoration in landscapes. New York: Springer, pp. 22-30.

Mather, A. S. 1992. The forest transition. Area 24 (4): 367-79.

McDermott, C. L., Hirons, M. and Setyowati, A. 2019. The Interplay of Global Governance with Domestic and Local Access: Insights from the FLEGT VPAs in Ghana and Indonesia. Society and Natural Resources: 1-19.

Meyfroidt, P., Vu, T .P. and Hoang, V. A. 2013. Trajectories of deforestation, coffee expansion and displacement of shifting cultivation in the Central Highlands of Vietnam. Global Environmental Change 23(5):1187-98.

OXFAM 2016. An Economy for the 1\% (Summary). OXFAM Briefing Papers 210.

Pressman, J. L. and Wildavsky, A. 1984. Implementation: How great expectations in Washington are dashed in Oakland; Or, why it's amazing that federal programs work at all, this being a saga of the Economic Development Administration as told by two sympathetic observers who seek to build morals on a foundation. Berkeley: University of California Press.

Racevskis, L. A. and Lupi, F. 2006. Comparing urban and rural perceptions of and familiarity with the management of forest ecosystems. Society and Natural resources 19(6):479-95.

Sotirov, M. and Winkel, G. 2016. Toward a cognitive theory of shifting coalitions and policy change: linking the advocacy coalition framework and cultural theory. Policy Sciences 49(2):125-54.

Steffen, W., Richardson, K., Rockström, J. et al. 2015. Planetary boundaries: Guiding human development on a changing planet. Science 347(6223):1259855.

Thompson, M., Ellis, R. and Wildavsky, A. 1990. Cultural theory. Boulder: Westview Press,

Tyrväinen, L., Silvennoinen, H. and Kolehmainen, O. 2003. Ecological and aesthetic values in urban forest management. Urban Forestry \& Urban Greening 1(3):135-49.

UN 1987. Report of the World Commission on Environment and Development: Our common future. New York: United Nations.

UNEP 2016. Global material flows and resource productivity. Assessment Report for the UNEP International Resource Panel.

Winkel, G. (ed.) 2017. Towards a sustainable European forest-based bioeconomy - assessment and the way forward. What Science Can Tell Us 8. Joensuu: European Forest Institute.

World Bank 2016. Forests create jobs and wealth. Available at: www.worldbank.org/en/news/ infographic/2016/03/16/forests-create-jobs-infographic (Accessed 28 March 2019). 
